\title{
Influence of Critical Thinking on Creativity When Using Mobile Devices for Learning
}

\author{
Arthur Firipis ${ }^{1}$, Siva Chandrasekaran ${ }^{2} \&$ Matthew Joordens ${ }^{1}$ \\ ${ }^{1}$ School of Engineering, Deakin University, Australia \\ ${ }^{2}$ Engineering Practice Academy, Swinburne University of Technology, Melbourne, Australia \\ Correspondence: Arthur Firipis, School of Engineering, Deakin University, Locked Bag 20000, Geelong, \\ Victoria, 3220 Australia.
}

Received: March 18, 2018

Accepted: April 4, 2018

Online Published: April 19, 2018

doi:10.20849/aes.v3i2.366

URL: https://doi.org/10.20849/aes.v3i2.366

\begin{abstract}
Learning using 1:1 mobile devices is a partnership between the user and the curriculum, where learning interventions are strategically integrated to foster critical thinking skills for effective problem solving. The purpose of this research study is to explore the question. How can 1:1 mobile technology be used to develop critical thinking skills and support creativity? The skill of problem solving is evidence of applied critical thinking during targeted learning. The literature review and focus group results, contextualise and aim to demonstrate how learners are using 1:1 mobile devices to develop critical thinking skills to achieve problem solving outcomes. Engineering courses that are using problem orientated design-based learning and are allowing students to use 1:1 mobile devices, need to support students by including targeted learning interventions. Learning interventions using active learning (self-directed learning) principles that are designed to teach critical thinking skills to achieve higher order problem solving outcomes for 'real world' solutions. Focus group results are included in this research study to highlight students' perceptions when using 1:1 mobile devices for learning as evidence of applied critical thinking skills.
\end{abstract}

Keywords: 1:1 mobile device technology, educational psychology, learning, critical thinking, and curriculum design

\section{Introduction}

Learning using 1:1 mobile devices is a partnership between the user and the curriculum, where learning interventions are strategically integrated to foster critical thinking skills for effective problem solving. However, critical thinking is not an innate skill and is at times at odds with the learner's skill level to use cognitively processes to think logically. If critical thinking skills are lacking, then it must be nurtured through the curriculum. The research question is explored, 'How can 1:1 mobile technology be used to develop critical thinking skills and support creativity?' Where the use of 1:1 mobile devices are being used to source information during the learning process, the sources must be tested to minimize information that may result in inaccurate conclusions. Therefore, to assist in the learning process where 1:1 mobile devices are being used, cognitive processes must be supported with the teaching of critical thinking skills. The skill of problem solving is evidence of effective application of applied critical thinking during targeted learning. In this article, critical thinking skills are examined and applied to show how student learning can be supported where the curriculum design intends to incorporate 1:1 mobile devices to achieve problem solving outcomes. Engineering courses that are using problem orientated design-based learning and are allowing students to use 1:1 mobile devices, need to support students by including targeted learning interventions. Learning interventions using active learning (self-directed learning) principles that are designed to teach critical thinking skills to achieve higher order problem solving outcomes for 'real world' solutions. Focus group results are included in this research study to highlight students' perceptions when using 1:1 mobile devices for learning as evidence of applied critical thinking skills.

\section{Research Methodologies}

In consultation with the research authors, a library search protocol was developed prior to the literature search commencing. A mixed search strategy via accessing electronic databases and drawing on library held hard copy resources was undertaken during 2017. The following electronic resources were accessed in the literature search: 


\section{EBSCO (http://search.ebscohost.com/)}

IEEE Digital Library (http://ieeexplore.ieee.org/) and

Google Scholar (http://scholar.google.co.uk/)

Keywords were used to facilitate searches: critical thinking, higher order thinking, active learning, self-regulated learning, learning motivation, learning theory, mobile technology, tablet, iPad; 1:1 mobile device, instruction, instructional, learning, and Engineering learning. Studies were included in the literature review if they were prepared by recognised peer reviewed academics and research published by a recognized academic publisher and contributed to explaining the application of critical thinking learning theories. Excluded from the literature search were studies not relevant to a higher education setting.

The guiding question for the literature review and focus group research is:

(1) 'How can 1:1 mobile technology be used to develop critical thinking skills and support creativity?'

The literature review was narrowed to thirty-one research studies from a total of 141 potential database and library sources (See reference list). The following discussion includes the critical thinking theories and empirical studies that historically contextualise and attempt to understand any links between technical skills, critical thinking and creativity when using 1:1 mobile devices. This literature review is limited to acknowledging that early critical thinking theorist and empirical studies were reporting without the knowledge of the future influence mobile technology would have on learning.

Further, supporting the literature review, a series of focus groups were conducted with results sourced from seventeen (17) university level engineering students enrolled in first to third year of study in 2017. Participants were aged between 18 to 35 years old ( 1 female and 16 males). The focus groups were comprised of volunteers recruited using approved research ethics guidelines for human research studies. Twenty questions were presented to the participants, and handwritten notes were taken to record responses. Data was de-identified, compiled and analysed using an Excel Spreadsheet. Responses then reported for the purpose of this research study.

1:1 mobile devices are defined as a portable handheld 1:1 device include iPad, mobile phone, Tablet or similar handheld Wi-Fi or Internet accessible device. Respondents of the focus group study (see Table 1. 1a and 1b-1:1 Mobile Device Usage) reported using the following 1:1 mobile devices for their learning.

Table 1. 1a and 1b-1:1 mobile device usage

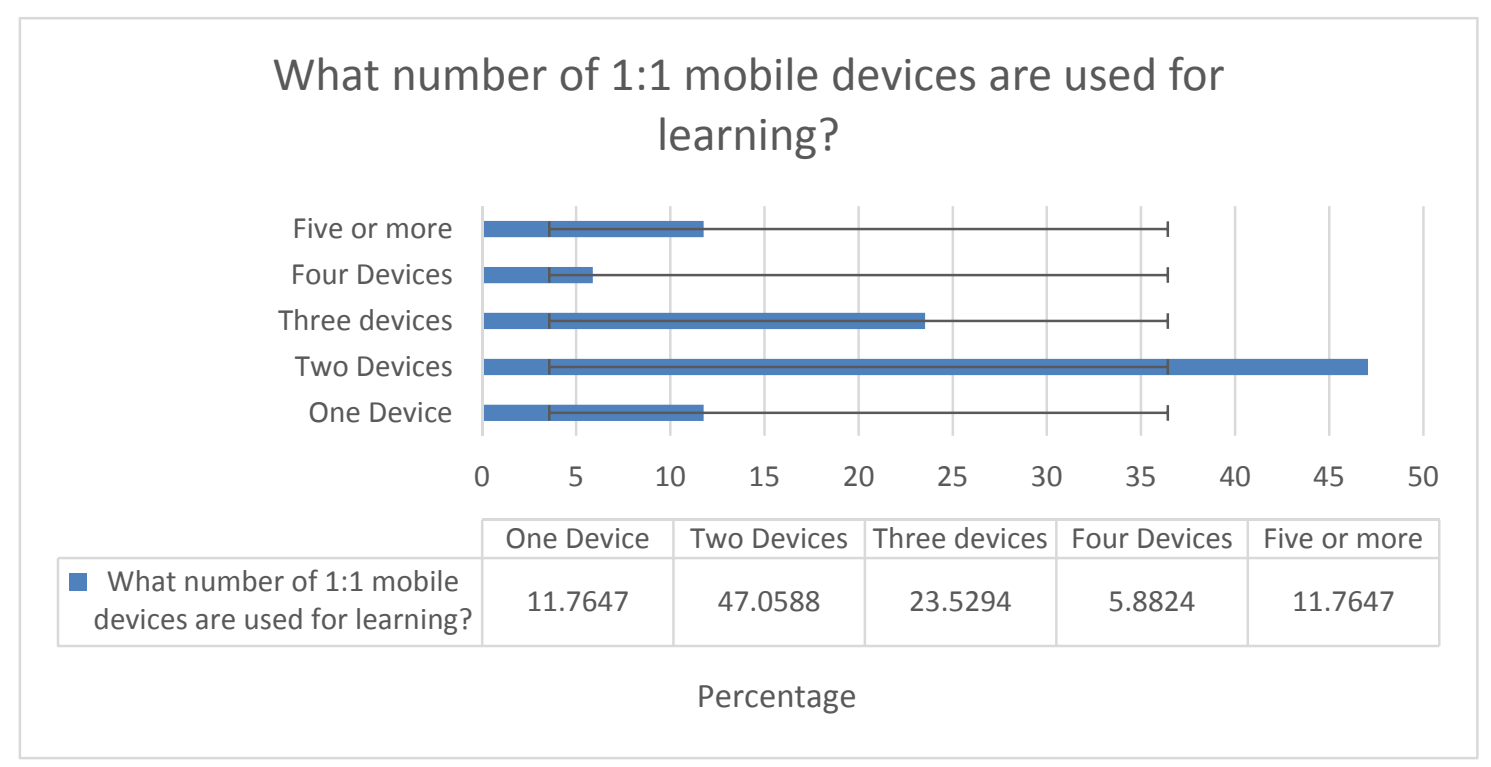




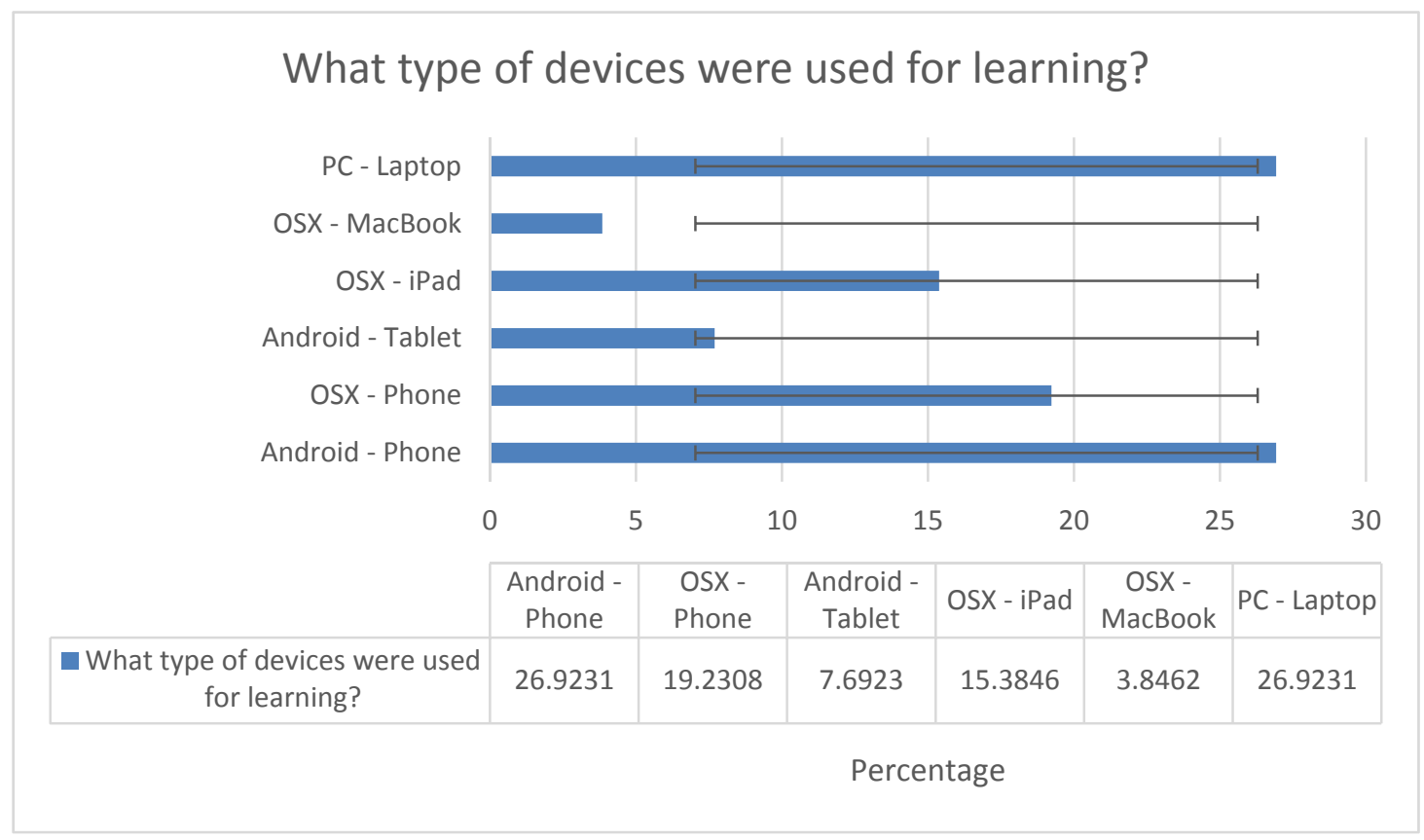

\section{Importance of Critical Thinking}

In the fifth century B.C.E., Greek philosopher, Socrates is credited with a method of examining using 'elenchus', a logical refutation method of eliciting truth by question and answer, especially as used to refute an argument. Also known as the 'Socratic Method', breaking down a problem down into questions, the answers to which lead to understanding the implications of the problem. Socratic Method results in answers that are difficult to refute, which Socrates believed it would lead to the truth. Socrates was responding to an immoral culture, which eventually was at odds with his Athenian society resulting in his ideas been ridiculed and put on public trial.

Critical thinking skills may lead to controversy and provides an opportunity for leadership skills to be developed. Effective leaders are critical thinkers and are able to challenge the status quo to derive solutions.

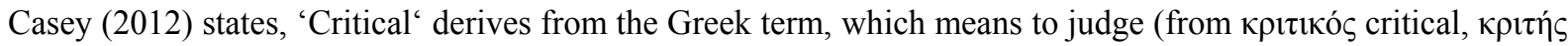
a judge; kpívelv to decide, judge). The word "critical' may have negative overtones in its common application, unfavourable criticism, fault finding, or censorious. However, judgments are not always negative, and the result of critical thinking may well be a process of reasoning for good. Therefore, critical thinking is necessary despite its ability to be the source of confrontation during a problem-solving activity. Accepting this reality within the learning space will provide an opportunity for the curriculum designer to challenge students through moral application when searching out the 'truth'.

Beyond the philosophical arguments, critical thinking skills extend beyond merely asking rhetorical questions that may or may not result in the most effective use of time; particularly when charging a client consultation fee to achieve a commercial solution to a 'real-world' problem.

Glaser (1941), states.

'Critical thinking...calls for persistent effort to examine any belief or supposed form of knowledge in the light of the evidence that supports it and the further conclusions to which it tends...[It] requires ability to recognize problems, to find workable means for meeting those problems, to gather and marshal pertinent information, to recognize unstated assumptions and values, to comprehend and use language with accuracy, clarity, and discrimination, to interpret data, to appraise evidence and evaluate arguments, to recognize the existence (or non-existence) of logical relationships ...to draw warranted conclusions and generalization at which one arrives, to reconstruct one's patterns of beliefs on the basis of wider experience, and to render accurate judgments about specific thinking and qualities in everyday life'

Ennis (1996) states critical thinking is a process, the goal of which is to make reasonable decisions about what to believe and what to do. Critical thinkers are disposed to do the following:

Seriously consider points of view other than their own 


\section{Seek and offer reasons}

Be well-informed

Endorse a position to the extent that, but only to the extent that, it is justified by the information available

Determine, and maintain focus on, the conclusion or question

Take into account the total situation

Be reflectively aware of their own basic beliefs

Discover and listen to other's views and reasons

Seek as much precision as the situation requires

Figure out the main point, issue, question or problem

Know the reasons offered in support of a conclusion and decide whether the reasons are acceptable before making a final judgment about an argument

Siegel (1988) defines the critical thinker as one who has a character which is inclined to seek, and to base judgment and action upon, reasoning; which rejects partiality and arbitrariness; committed to the objective evaluation of relevant evidence; and which values such aspects of critical thinking as intellectual honesty, justice to evidence, sympathetic and impartial consideration of interests, objectivity, and impartiality.

Dewey (1933), described 'thinking' as a sequenced chaining of events. He states,

'This productive process moves from reflection to inquiry, then to critical thought processes that, in turn, lead to a "conclusion that can be substantiated" by more than personal beliefs and images. Thought can straighten out entanglements, clear obscurities, resolve confusion, unify disparities, answer questions, define problems, solve problems, reach goals, guide inferences, shape predictions, form judgments, support decisions, and end controversies.'

Kauchak and Eggen (1998) reemphasize Dewey's (1933) focus that it is important to teach students how to think about their own thinking processes. Jacobs, (1994) and Tversky \& Kahneman (1982) argue, when learners become aware of their thinking processes, they better understand how their own personality and values influences their choices during problem solving. McPeck (1990) states, 'It is just as important to teach the structure of a discipline (p. 49) as to teach thinking skills, and that "most problems are in fact 'multicategorical' and not domain-specific" (p. 113).'

Kahneman et al., (1982) highlights factors such as culture, experience, preferences, desires, interests, and passions can radically alter the decision-making process. He continues to state, "Nevertheless, with time and more experience in systematic thinking, individuals and groups can develop the principles to guide decision making so that 'a certain manner of interpretation gets weight, authority' as long as "the interpretation settled upon is not controverted by subsequent events".

Dewey (1933) reminds us of the necessity to form learning habits through the 'Training of the mind'. He states, 'These habits are not a gift of nature (no matter how strong the aptitude for acquiring them); since, moreover, the casual circumstances of the natural and social environment are not enough to compel their acquisition, the main office of education is to supply conditions that make for their cultivation.' Dewey (1933) warns against dismissing the need to model and teach the discipline of logical thinking; curiosity, inference, experimenting, and testing of ideas as a natural expression of intellectual power. For example, an experienced engineer inductively identifies a field problem based on initial client brief, however, will postpone his conclusion in order that further tests and fact finding can be done to deduce a solution.

Dewey (1933), Glaser (1941), Siegel (1988), Ennis (1996) and Casey (2012) agree that critical thinking is important, however, it is not clearly articulated what it is and how it should look within the curriculum. Further, we often assume we are fostering it in our classrooms when there is little evidence to support this view.

Firipis et al. (2017) after interviewing engineering students using a focus group research instrument, students reported held pre-perceptions about their use of 1:1 mobile devices for learning (see Table 2. Pre-perceptions of using 1:1 Mobile Device). Whilst remote access was perceived to be its primary purpose, students were significantly educated to identify various practical benefits as an important tool to aid learning. Notably, to access and create digital artefacts, and the benefits of social media to connect within and beyond the learning space. 
Table 2. Pre-perceptions of using 1:1 mobile device

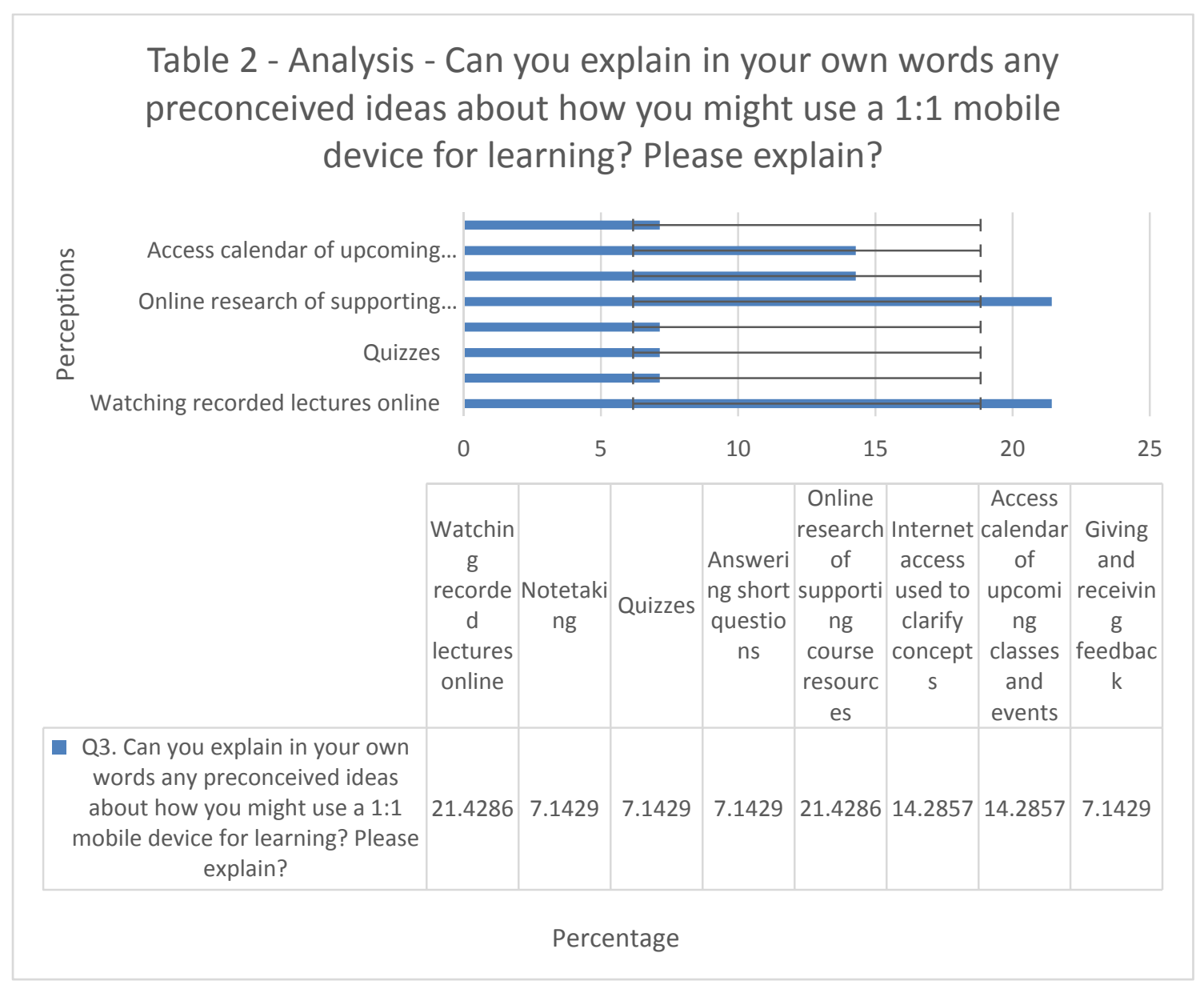

\section{Table 2. Focus group responses: Can you explain in your own words and pre-perceptions about how you might use a 1:1 mobile device for learning? Please explain?}

To display any online lecture notes

Taking notes. Research. Accessing and sharing documents

My preconceived ideas before starting university were that my devices would be an irreplaceable tool that can provide help and support for research

Quizzes, communication between groups

I intend to use mobile devices when I was not able to sit in front of a computer to attend my seminars and studios

Notes, Answering questions

Use for researching concepts and ideas

Being able to receive news from my teachers would be great. I find not being able to see the messages straight away is not helpful. Check things on the go

Videos - lecture notes and lectures. Applications for iPads. Possible schedule

Curriculum designers that intend to incorporate 1:1 mobile devices to support learning to gather data need to scaffold how 'inductive and deductive' thinking processes should be applied when undertaking problem solving. It may be necessary to intentionally expose learners to critical thinking processes as a stand-alone unit of study to develop a culture of what constitutes 'higher order thinking' and its practical application beyond theory using appropriate industry vocabulary, language and contextualised professional values.

\section{Preparing Learners for Problem Solving}

Elder and Paul (2009) states, 'Within every subject and field pursue specific purposes, ask certain kinds of questions, use certain kinds of information, make certain kinds of inferences, take for granted certain beliefs (or 
begin with certain assumptions), are guided by and develop certain kinds of concepts, principles and theories, foster certain kinds of viewpoints, and think through implications and consequences within the subject or discipline.' The following checklist is presented to focus the learning;

What is the main purpose or goal of studying this subject? What are people in this field trying to accomplish?

What kinds of questions do they ask? What kinds of problems do they try to solve?

What types of inferences or judgments do they typically make? (Judgments about...)

How do they go about gathering information in ways distinctive to this field?

What are the most basic ideas, concepts or theories in this field?

What do professionals in this field take for granted or assume?

How should studying this field affect my view of the world?

What viewpoint is fostered in this field?

What implications follow from studying this discipline? How are the products of this field used in everyday life?

Reference: Elder, L \& Paul, R. (2009) - The thinker's guide to analytic thinking: how to take thinking apart and what to look for when you do (p.5, 34). Dillon Beach: Foundation for Critical Thinking Press.

In contrast, Elder and Paul (2009) argue the following exemplars of critical thinking should be present, contrasting the difference between intellectual standards (text bolded) and their elements of reasoning (text underlined) as evidence of critical thinking.

Logically and deeply comparing and contrasting important concepts

Detailing significant similarities and differences in points of view

Examining or evaluating assumptions for justifiability

Distinguishing relevant from irrelevant information

Making plausible inferences, predictions, or interpretations

Exploring logical implications and consequences

Conceptualizing situations and issues reasonably

Formulating questions precisely

Reference: Elder, L. \& Paul. R. (2008). The Thinker's Guide to Intellectual Standards: the words that name them and the criteria that define them. Dillon Beach: Foundation for Critical Thinking Press.

In 2009, 1:1 Mobile technologies were in their infancy, yet applying critical theory to learning with the use of 1:1 mobile device technologies in the current environment, presents a challenge due to the personal learning space that exists within the technology. Applying targeted learning interventions using the underlying critical thinking and cognitive theory explaining thought processes, may help educators and students to realize their own need to self-regulate and become aware of the need to apply 'intellectual standards' and show evidence of 'elements of reasoning' when undertaking problem solving activities.

\section{Barriers to Critical Thinking When Using 1:1 Mobile Devices}

Paul and Elder (2007) identify a barrier that oppositionally hinders critical thought, egocentric 'and sociocentric' thought.

Egocentricity is an influence that uses 'self-centered' world views with a self-interest motivation that creates perceptions that are driven by one's own desires, values, and beliefs (seeming to be self-evidently correct or superior to those of others), blindly critical and unconsciously judging situations during the critical thinking process.

Paul and Elder (2007) argue socio centricity is the belief of one's own group or culture is superior to another. It perceives other people, groups or cultures from the perspective of one's own reference group. Accepting the logic of the group is integral in sustained membership or acceptance within the norms of the group. As part of this socialization process, they (largely uncritically) absorb group ideologies. Non-conformists are considered disloyal and are rejected or punished.

Egocentricity and socio centricity tendencies hinder individual and group behaviour to bring about critical 
learning spaces with independent thought to solve problems.

Table 3. Reasons why 1:1 mobile devices may not be helpful for learning and responses

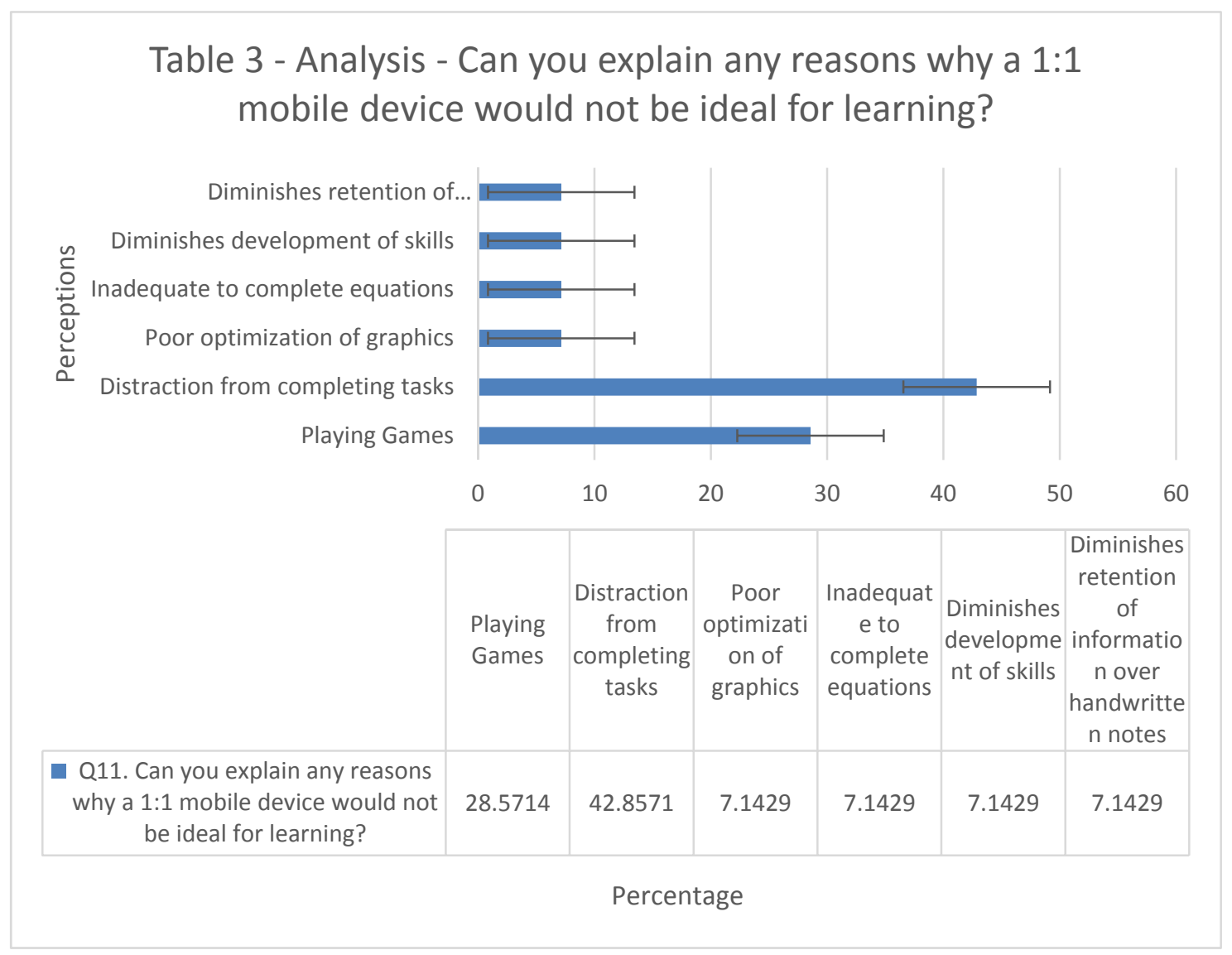

Table 3. Focus group responses: Can you explain any reasons why a 1:1 mobile device would not be ideal for learning?
Possible distractions
It would give students a way to play games and do things that aren't related to the course
Can be a distraction from the task at hand
Lack of resolution, content not optimized for mobile devices
Cannot do equations easily on 1:1 device
It can provide distractions in classroom or laboratory environments and is harder to use for very practical (Hands-on) tasks
Distractions. (Removed) Sync and D2L are not optimized for mobile, so any activities take longer to complete
Easily able to distract while using one as there is so much functionality for the device to be used differently
Can decrease retention of information as compared to handwritten notes

In its' subtly, 1:1 mobile device technologies may provide a space that prevents knowledge from having free access and critical tests applied, unless the curriculum explicitly supports clear guidelines about its usage for learning. Access to the World Wide Web and subscription to social online discussion groups can be a positive or negative to sustaining an open learning environment. Firipis et. al. (2017) reported learners held perceptions that 1:1 mobile devices can be a distraction during learning, including the temptation to play games instead of listening (see Table 3. Reasons why 1:1 devices may not be helpful for learning and responses. Other hindrances such as technology not optimized to view learning resources effectively in the classroom, inability to facilitate 
answering complex mathematical problems, and perceptions that it may diminish the learner's ability to retain information over taking handwritten notes in exercise books. Course designers may need to support learners whose inability to think critically is diminished due to their reliance on a Bring Your Own Device (BYOD) or supplied 1:1 mobile device within the learning environment.

\section{Creativity From Critical Thinking}

Elder (2012) explored the idea that critical thinking is oppositional to creativity of thought, however, to separate what is teachable to that which is not, is a fallacy. The mind is not two distinct beings, but one. The truth is, there is no formula that can produce creative geniuses, or to guarantee the production of innovative ideas. Elder (2012) concludes, '...critical and creative thoughts are the result of imagination and artistic intellectual inventiveness; the high-quality thought simultaneously produce and assess, both generate and judge the products it fabricates'.

Further, mastering technical skills and reapplying them to respond creatively to a need is highlighted in the Co-founder of Apple Computers memoirs;

Wozniak, S. (2014) states. 'I first experienced BASIC in high school that same year. We didn't have a computer in the school but GE, I think, brought in a terminal with students were given some pages of instruction and we wrote some very simple programs in BASIC. I saw that this was a very simple and easy-to learn language to start with, but that terminal was only in our school for a few days. I was asked by our head maths teacher to write a page on why I thought this would be a good thing for our school to have. I did indeed write a page about logical thinking and problem solving but our school didn't go ahead and get into the time-share program. I was a fan of computer games and knew that as soon as I had a computer of my own I would want to type in all these games to play. Judging by my own feelings, I assumed that this would be a key to starting a home computer revolution.'

Reference: Wozniak, S., (2014)-How Steve Wozniak wrote BASIC for the original Apple from scratch. Cited $\begin{array}{llll}\text { from } \quad \text { website } & \text { on } 28 / 12 / 17\end{array}$ https://www.gizmodo.com.au/2014/05/how-steve-wozniak-wrote-basic-for-the-original-apple-from-scratch/

\section{Critical Thinking Standards}

Paul and Elder (2009) argue that critical thinking standards need to be integrated across the curriculum to develop the learner's vocabulary and knowledge of knowing when critical thinking is occurring. Also, to disperse any misconceptions about what critical thinking is not. Paul and Elder (2009) have developed eight Elements to assist curriculum developers to identify when effective critical thinking questioning is being used by a learner. The eight elements include;

What is the Purpose?

What is the Point of View?

What are the Assumptions?

What are the Implications?

What Information is needed?

What Inferences are being made?

What is the most fundamental Concept? and,

What is the Question that is being answered?

Paul and Elder (2009) demonstrated in Figure 1. 'Framework for Critical Thinking' shows the connection between 'Standards, Elements and Intellectual Traits' as evidence of critical thinking. The authors use of a common vocabulary is intended to assist learners to develop and exhibit metacognitive critical thinking skills as they proceed through the three or four-year curriculum design. 


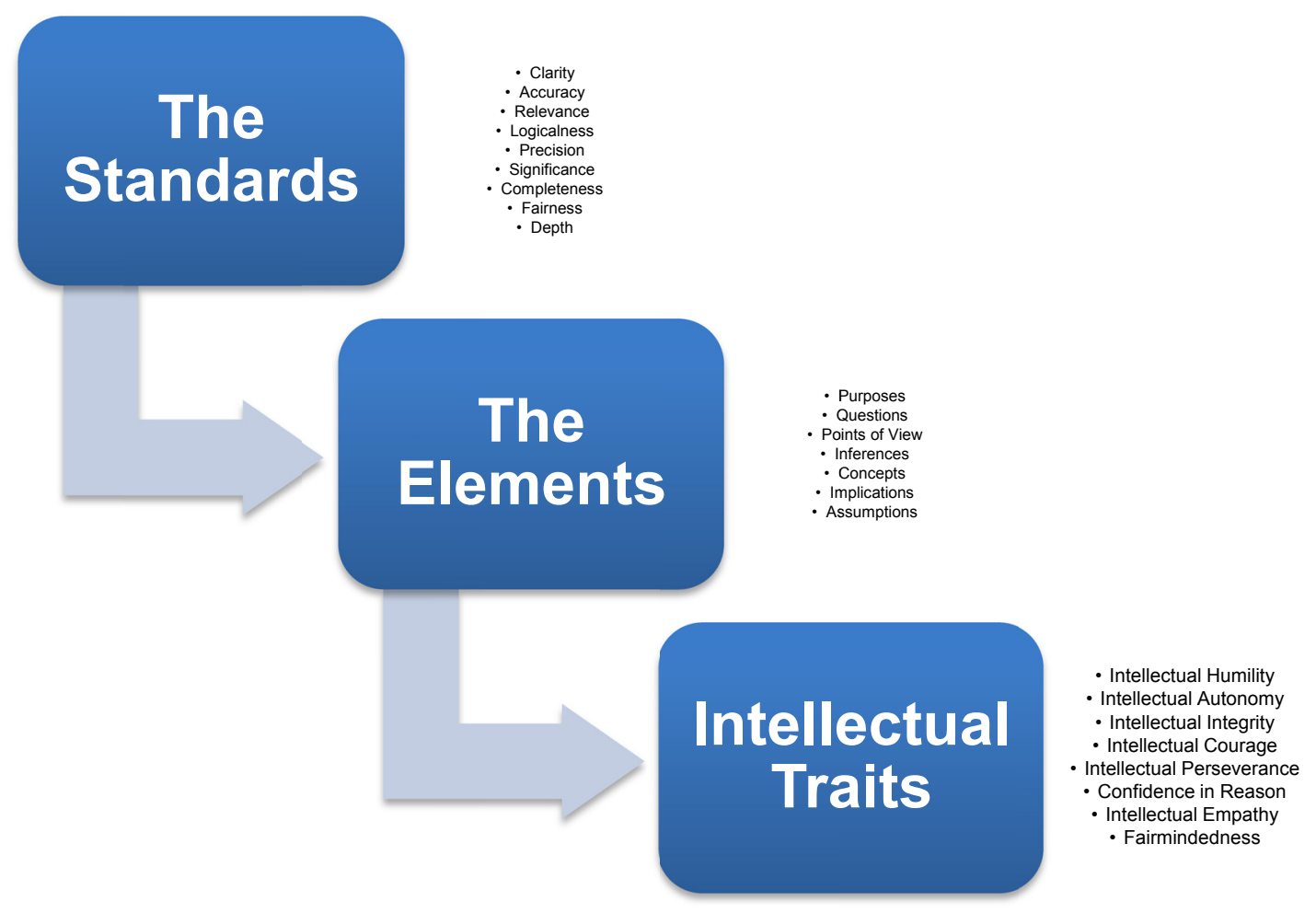

Figure 1. 'Framework for critical thinking'

Reference: Paul, R. W. \& Elder, L. (2009) -The miniature guide to critical thinking concepts \& tools (6th ed.). Dillon Beach, CA: The Foundation for Critical Thinking. p. 19

\section{Digital Literacy to Support Critical Thinking}

Marzano (1994) developed 'Dimensions of Thinking' (see Table 4 - Dimensions of Thinking) to provide an insight into the complexity of language to understand the symbiotic relationship between critical thinking and creativity; and to provide a framework for educators to prepare curriculum sequences. 
Table 4. Dimensions of thinking

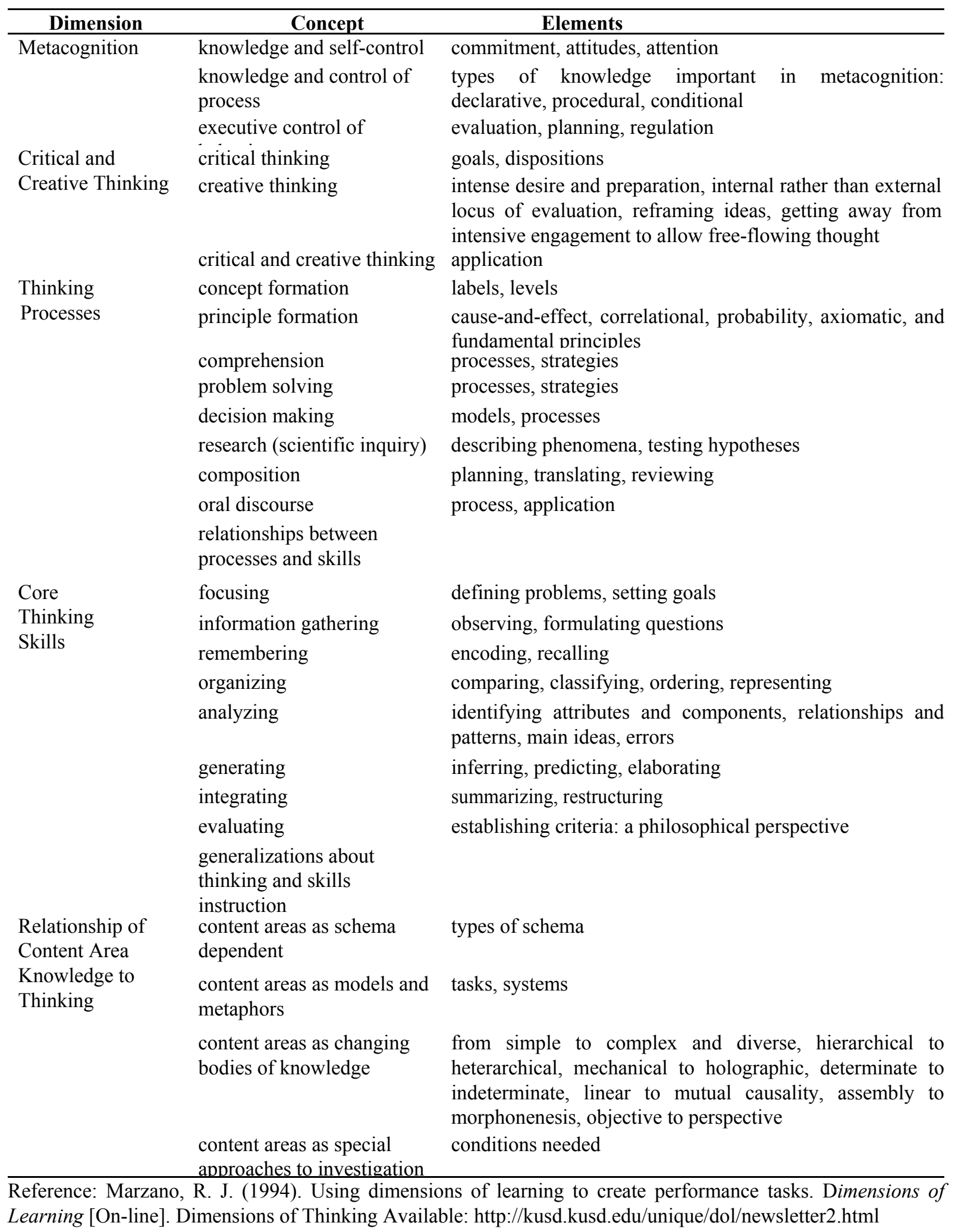

King et al. (1990) identified from the literature vocabulary terms used to describe higher order thinking (See Table 5. Vocabulary used to describe Higher Order Thinking). Whilst the list is not exhaustive, it demonstrates the importance of developing common understandings within the curriculum. 
Table 5. Vocabulary used to describe higher order thinking

\begin{tabular}{|c|c|}
\hline Terms & Descriptions \\
\hline comprehension & $\begin{array}{l}\text { the "mental operations involved in thinking; the biological/neurological processes of the } \\
\text { brain that facilitate thought" (Alvino cited in Cotton, 1997, p. 3); "all of our mental } \\
\text { processes, such as perception, memory, and judgment" (Crowl et al., 1997, p. 36) } \\
\text { the process by which individuals "construct meaning from incoming information" (Crowl } \\
\text { et al., 1997, p. 149) }\end{array}$ \\
\hline $\begin{array}{l}\text { creative } \\
\text { thinking }\end{array}$ & $\begin{array}{l}\text { generating and producing ideas through brainstorming, visualizing, associating } \\
\text { relationships, making analogies, inventing, inferring, and generalizing (Fogarty \& } \\
\text { McTighe, 1993) }\end{array}$ \\
\hline $\begin{array}{l}\text { critical } \\
\text { thinking }\end{array}$ & $\begin{array}{l}\text { an attitude of suspended judgment, logical inquiry, problem solving, evaluative decision or } \\
\text { action (National Council on Teacher Education's [NCTE] Committee on Critical Thinking } \\
\text { and the Language Arts as cited in Carrol, n.d.); skillful, responsible thinking that facilitates } \\
\text { good judgment, relies upon criteria, is self-correcting and sensitive to context (Lipman cited } \\
\text { in Legg, 1990); skepticism, curiosity; questioning of beliefs, aims, definitions, conclusions, } \\
\text { actions, appraisal of frameworks or sets of criteria by which judgments are made (Patrick, } \\
\text { 1986) }\end{array}$ \\
\hline graphic frame & $\begin{array}{l}\text { an organizing pattern to visually represent relationships; serves as a medium for } \\
\text { organizing new information and patterns of relationships (e.g., flowcharts, cartoons, } \\
\text { symbols, diagrams, time lines, grids, graphs, concept maps, chains, towers, circles, } \\
\text { pyramids, boxes) (Clarke, 1990) }\end{array}$ \\
\hline $\begin{array}{l}\text { higher order } \\
\text { thinking }\end{array}$ & $\begin{array}{l}\text { understanding of facts, concepts, principles, and procedures (Haladyna, 1997); analysis, } \\
\text { synthesis, and evaluation (Bloom, 1956) }\end{array}$ \\
\hline inquiry & $\begin{array}{l}\text { investigating beliefs or forms of knowledge, taking care to consider the grounds that } \\
\text { support them, and the conclusions drawn from them (Dewey, 1933) }\end{array}$ \\
\hline insight & $\begin{array}{l}\text { "seeing" a correct solution; sudden coherency or change in perceptions, feeling, thought } \\
\text { (Gruber, 1995); the "aha" experience, from a state of not knowing to knowing (Gick \& } \\
\text { Lockhart, 1995) }\end{array}$ \\
\hline metacognition & $\begin{array}{l}\text { mental process of being aware of monitoring, supervising, organizing, and making } \\
\text { executive decisions about one's own thinking process (Crowl et al., 1997); thinking about } \\
\text { thinking, the use of information and strategies to solve problems (Pogrow, 1990; Pogrow } \\
\& \text { Buchanan, 1985); mind's management system; ability of the mind to control its own } \\
\text { processing of how we think (Sternberg; Gagné; Flavell; Presseisen; all cited in Costa, } \\
\text { 1990) }\end{array}$ \\
\hline $\begin{array}{l}\text { problem } \\
\text { solving }\end{array}$ & $\begin{array}{l}\text { application of more than one rule/more than four concepts to solve problems to } \\
\text { situations with multiple variables, multiple relationships (King, Rohani, \& Goodson, } \\
\text { 1997); combines two or more rules to solve a problem (Gagné, Briggs, \& Wager, 1988) }\end{array}$ \\
\hline $\begin{array}{l}\text { rational } \\
\text { thinking }\end{array}$ & $\begin{array}{l}\text { the interdependent skills of creative thinking, critical thinking, and problem solving (Ennis } \\
\text { cited in Lewis \& Smith, 1993) }\end{array}$ \\
\hline scaffolding & $\begin{array}{l}\text { support and guidance gradually removed until one can work independently (Rogoff; } \\
\text { Rogoff, Malkin, \& Gilbride cited in Crowl et al., 1997) }\end{array}$ \\
\hline schemata & $\begin{array}{l}\text { systems of relationships between concepts (Crowl et al., 1997); complex networks of } \\
\text { related knowledge (Rumelhart cited in Costa, 1990); cluster of knowledge associated } \\
\text { with a type of problem; typical solution procedures (Gick \& Lockhart, 1995) }\end{array}$ \\
\hline scripts & $\begin{array}{l}\text { simple routines developed through repeated practice of elaborate reasoning procedures } \\
\text { (Galambos cited in Costa, 1990) }\end{array}$ \\
\hline transfer & $\begin{array}{l}\text { "the ability to apply thinking skills taught separately to any subject" (Alvino cited in } \\
\text { Cotton, 1997, p. 3) }\end{array}$ \\
\hline
\end{tabular}

Reference: King, J., Rohani, F., and Goodson, L., (1998)-Higher Order Thinking Skills - Definition -Teaching Strategies-Assessment. Educational Services Program. Centre for Advancement of Learning and Assessment. www.cala.fsu.edu/ files/higher_order_thinking_skills.pdf. 
$\mathrm{Ng}$ (2013) argues digital literacy is an essential skill to assist learners to think critically; the ability to analyze the relationship between texts, power and social justice by challenging the underlying values and beliefs hidden within the surface of digital texts.

Lea and Jones (2011) acknowledges the importance of integration between digital textuality and technological practices, highlighting the importance of the role curriculum designers play in ensuring information is accessible to learners using mobile technology.

$\mathrm{Ng}$ (2013) makes an observation that an obstacle to the support of critical thinking using digital texts is the inconsistency of curriculum designers' development and choice of learning applications for use on 'MLearning' (Mobile Learning using 1:1 mobile technology) devices.

$\mathrm{Ng}$ (2013) states, 'Being digitally [mobile] literate will prepare individuals to adapt to new and emerging technologies more easily and as mobile technologies are one of the fastest growing areas of technology, equipping individuals with mLearning literacy should enable them to pick up newly emerging semiotic systems and resources for communication as they arise and adapt to new mind-sets and practices that come with this growth.'

Reference: Ng, W. (2013)-Conceptualizing mLearning Literacy. International Journal of Mobile and Blended Learning, Vol. 5,1, p. 8.

\section{Critical Thinking Interventions}

King, et al. (1998) argued teaching strategies that model through scaffolding (by giving learners support at the beginning of a lesson and gradually releasing them to encourage independent thought) to actively engage with the learning by considering the context, meta-cognitional processes, application of procedural knowledge, use comprehension skills, gaining insight through sharing of ideas, using creativity, applying intelligence, problem solving, critical thinking, evidence gathering to help students to recognize good teaching and learning in practice.

King et. al. (1998) states, 'Teacher- and/or student-generated questions about dilemmas, novel problems, and novel approaches should elicit answers that have not been learned already. Sincere feedback providing immediate, specific, and corrective information should inform learners of their progress. Small group activities such as student discussions, peer tutoring, and cooperative learning can be effective in the development of thinking skills. Activities should involve challenging tasks, teacher encouragement to stay on task, and ongoing feedback about group progress. Computer-mediated communication and instruction can provide access to remote data sources and allow collaboration with students in other locations. It can be effective in skill building in areas such as verbal analogies, logical thinking, and inductive/deductive reasoning.'

Reference: King, J., Rohani, F., and Goodson, L., (1998)-Higher Order Thinking Skills-Definition -Teaching Strategies-Assessment. Educational Services Program. Centre for Advancement of Learning and Assessment. www.cala.fsu.edu/ files/higher_order_thinking_skills.pdf.

King et. al. (1998) concludes it is necessary to select learning interventions that can show evidence of critical thinking occurring, for example, using multiple-choice questions, ranking order of importance and matching questions; short- answer, extended essay response, group tasks with performance criteria. Further, providing opportunity for learners to give reasons and/or show the logical steps taken that led to the problem been solved. The curriculum design needs to find a balance between unfamiliarity of the topic, development of inquiry questions and having adequate prior knowledge to attempt the activity successfully. Using 1:1 mobile device technology and associated software applications can support learners to demonstrate evidence of their use of critical thinking skills.

For example, 'Socrative' is an interactive visual learning tool, accessible from the proprietor's online Internet server, allowing subscribers via their 1:1 mobile device to create interactive digital artefacts in the classroom. Firipis et. al. (2017) reported responses from a focus group study that learners prioritize their perceptions of the usefulness of using a 1:1 mobile device for learning. In Table 6. Perceived Benefits of 1:1 mobile device Apps for Learning, using software applications (APPS) to complete revision quizzes and recording notes supported the learning. Having access to the Internet for browsing to potentially assist with finding correct responses to quizzes is a trend finding its way into the learning space. Curriculum designers need to consider how quiz questions are framed to promote critical thinking, rather than using quiz software APPS to entertain with quick responses accessible immediately from browsing the Internet. 
Table 6. Perceived benefits of 1:1 mobile device Apps for learning and responses

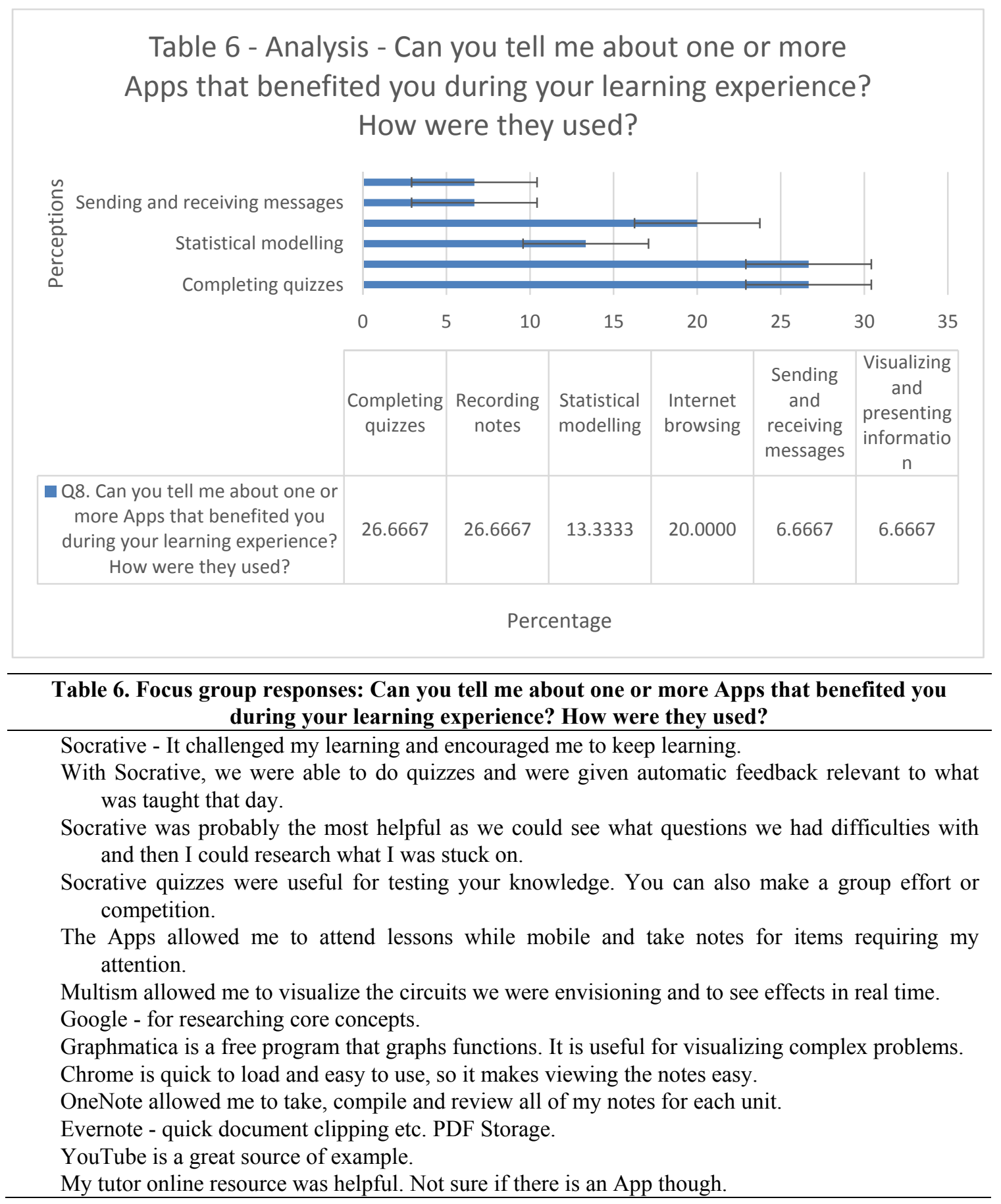

The instructional designer models to the learners how to generate questions and invite feedback to actively support critical thinking skills. Due to its instant feedback, the lecturer can identify areas of weakness and strengths and modify the learning. The aim is to have students use the tool to develop lines of questioning themselves as an expected learning approach.

Welch et. al. (2015) reported an improvement in critical thinking skills as a result of implementing the Elder-Paul (2009) 'Framework of Critical Thinking' model across year levels. Welch (2015) discusses the following case studies as examples of learning interventions to foster critical thinking; NASA moon survival problem requiring algebraic word problems. Hyatt Regency Walkway Collapse where 114 people died due to structural failure. Both these examples required group work and the application of previously learned technical 
skills in engineering.

\section{Creativity Through Critical Thinking Using Social Media}

Bourlard, Krishnamurthy, Sun, Zhao, and Liu, (2012) argue Internet facilitated social circles, sharing of information and experience, and organized online learning groups such as Facebook, provides a rich opportunity to apply critical thinking and express creativity. Wodzicki, Schwämmlein and Moskaliuk (2012) argue students using social media platforms can connect to formal and informal learning spaces meet specific group and individual intellectual needs. Cain and Policastri (2011) affirm the trend amongst critical thinkers who are using social media applications to engage creatively in online teaching and learning. Learning communities through social media tools such as collaborative editing is becoming "a 'new' learner -centred pedagogy" that promotes learner-driven content creation and collaborative knowledge sharing.

For example, Chang-Hwa Wang and Cheng-ping Chen (2013) conducted a social media experiment using Facebook, recording responses from participants using a reflexive log. The following observations about the importance of student's learning conditions were observed as an important interaction for critical thinkers.

Learning motivation-Facebook interaction promoted positive peer interaction.

Learning activities-Facilitation of communication, collaboration and resource sharing within a virtual environment promoted privacy, flexibility and adaptivity.

Learning style-Students became participants during the learning process rather than listeners, and gained experience how to critically think about instructional information.

Peer mentoring and social media-Peer tutoring where a student instructs another on material in which the first is an expert and the second is a novice.

Many of the supporting reasons mentioned by Chang-Hwa Wang and Cheng-ping Chen (2013) are common across different learning spaces. Firipis et. al. (2018) reported from focus group responses similar learning priorities perceived by learners (see Table 7. Benefits perceived for using 1:1 Mobile Device and responses). Interestingly, reducing anxiety (stress) was reported as a benefit as 1:1 mobile devices are perceived as an effective tool to organize individual learning resources and spaces.

Pachler (2010) reported pedagogical benefits of mobile devices in that they allow real world critical thinking and creativity, which contributes to the authenticity of the learning. Construction of digital artefacts can be shared, peer critiqued and co-construction, making learning more conducive to developing critical thinking skills (see Table 7). Chan et al., (2006) characterized this form of learning as 24/7 seamless learning. Wong \& Looi, 2011; Wong, Milrad, \& Specht, (2015) have reported the benefits seamless learning has provided to facilitated formal and informal learning, individual and social, and physical and digital spaces, accessible using mobile technologies.

Kukulska-Hulme \& Traxler, (2013) argue mobile technologies can enhance digital literacy from real world interactions into the classroom. Pavlenko, (2009) also acknowledged the importance of grammatical vocabulary, such as verbs, nouns, and adjectives, taken from the real world does support critical thinking within the learning space. Koh et al., 2013; Ogata et al., (2011) further emphasized the value of taking photos or video clips of what is happening in the real world and using these digital resources to become evidence of learner creativity as an expression of demonstrating a deeper understanding about the importance of language and specific vocabulary. Wong (2013) reported similar findings where creative use of vocabulary-based scenarios using photos and video clips, improved technical skills through sentence or paragraph construction about the recorded enactments as an expression of creativity when learning a new language. 
Table 7. Perceived benefits of using 1:1 mobile device for learning and responses

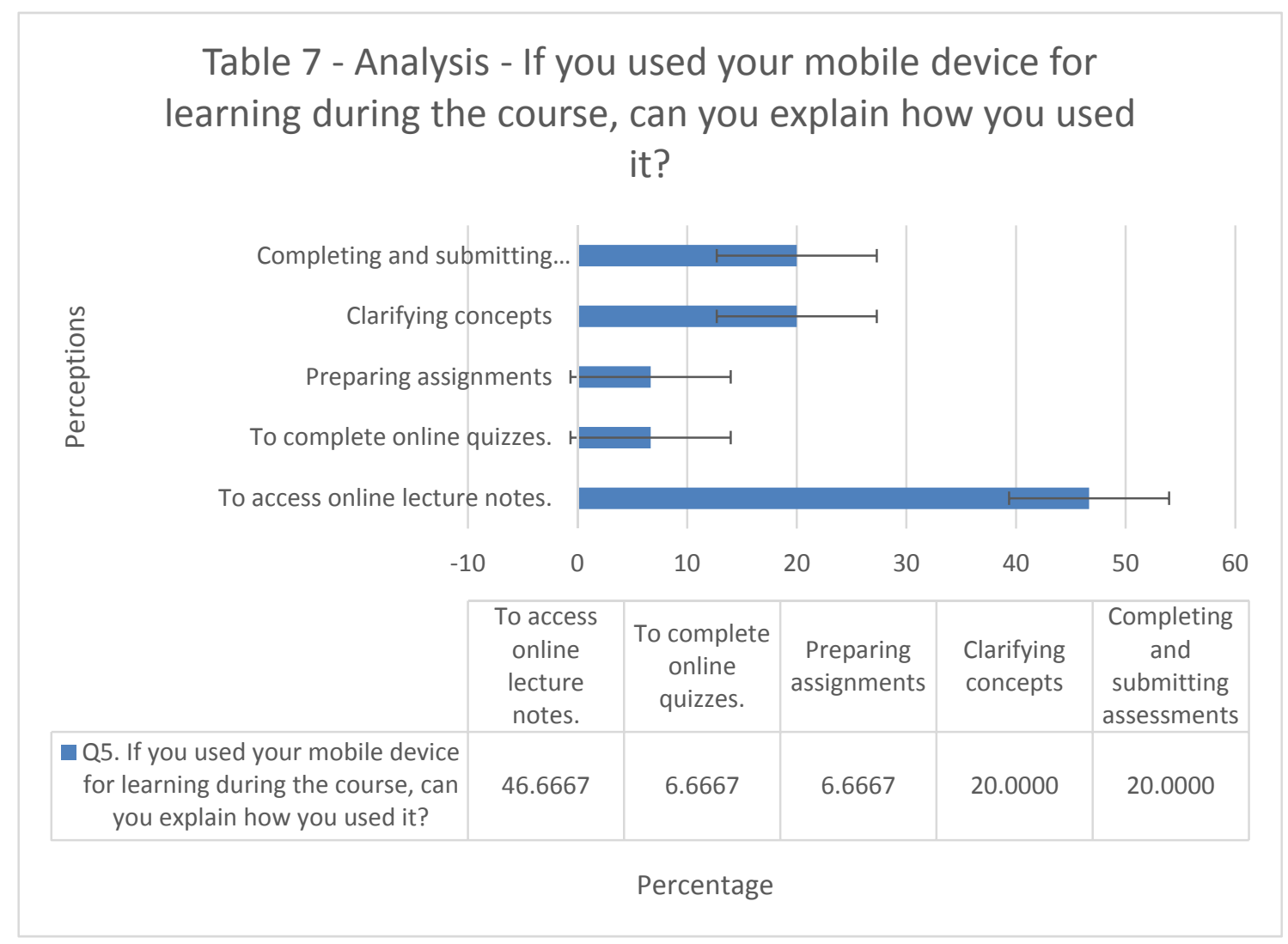

Table 7. Focus group responses: If you used your mobile device for learning during the course, can you explain how you used it?

I used my laptop to display lecture notes and to display the online questions. I used my phone to display online questions.

Writing up assignments. Revisiting lecture slides. Further research.

I used it to look up aspects of the lecture that I was unsure about as well as it was used to further explore ideas that were covered.

Used for doing Socrative quizzes.

Reviewing study material (text and video) by use of a tablet when I finished work.

Reading notes.

Researching Unit core concepts.

Communicating with group members.

Understanding how different components work.

I used my laptop during the vast majority of classes and lectures to access unit resources, such as notes, and also for any digital work for assessment tests. I did not use it to take notes.

View lecture notes during lectures (not having to look up then down as often, easier on eyes especially with small text). Photos and written notes.

Used it to show the lecture notes as I used a notebook to actually write everything down.

Watching classes, taking notes, writing and submitting assignments.

Mostly to re-watch lectures, also some examples.

Watching videos, note taking.

Firipis et. al. (2017) reported results from a focus group study showing higher education engineering learners perceived other benefits from using a 1:1 mobile device (see Table 8. Other reasons for using 1:1 Mobile Device and responses). Firstly, curriculum designers who accept the presumption held by learners that their success may not be guaranteed despite the effort undertaken to provide sufficient structure and details to scaffold the student to graduate with the skills and knowledge needed to result in successful employment. Learners are using their 
initiative to use their 1:1 mobile device to access online resources (internally and externally) to 'test' and 'clarify' course concepts. In many cases, learner's may be attempting to find alternative ways to process and understand difficult course content, or to overcome a perceived barrier to their learning. For example, overseas students who have difficulty with the English language, or alternatively local students having difficulty comprehending a visiting or newly transferred lecturer. Learning styles also are an important consideration whereby courses presupposed on specific industry norms and values, may not be easily adopted by a newly enrolled learner. In Table 8. Other reasons for using 1:1 Mobile Device, respondents are articulating a desire to engage with their learning, however, hold perceptions that they cannot solely rely on the potentially outdated course content to be successful. Curriculum designers who can leverage this to support their learners, for example, providing references for further reading or allocating time to allow students to share their extended knowledge gained from online sources.

Table 8. Other reasons for using 1:1 mobile device and responses

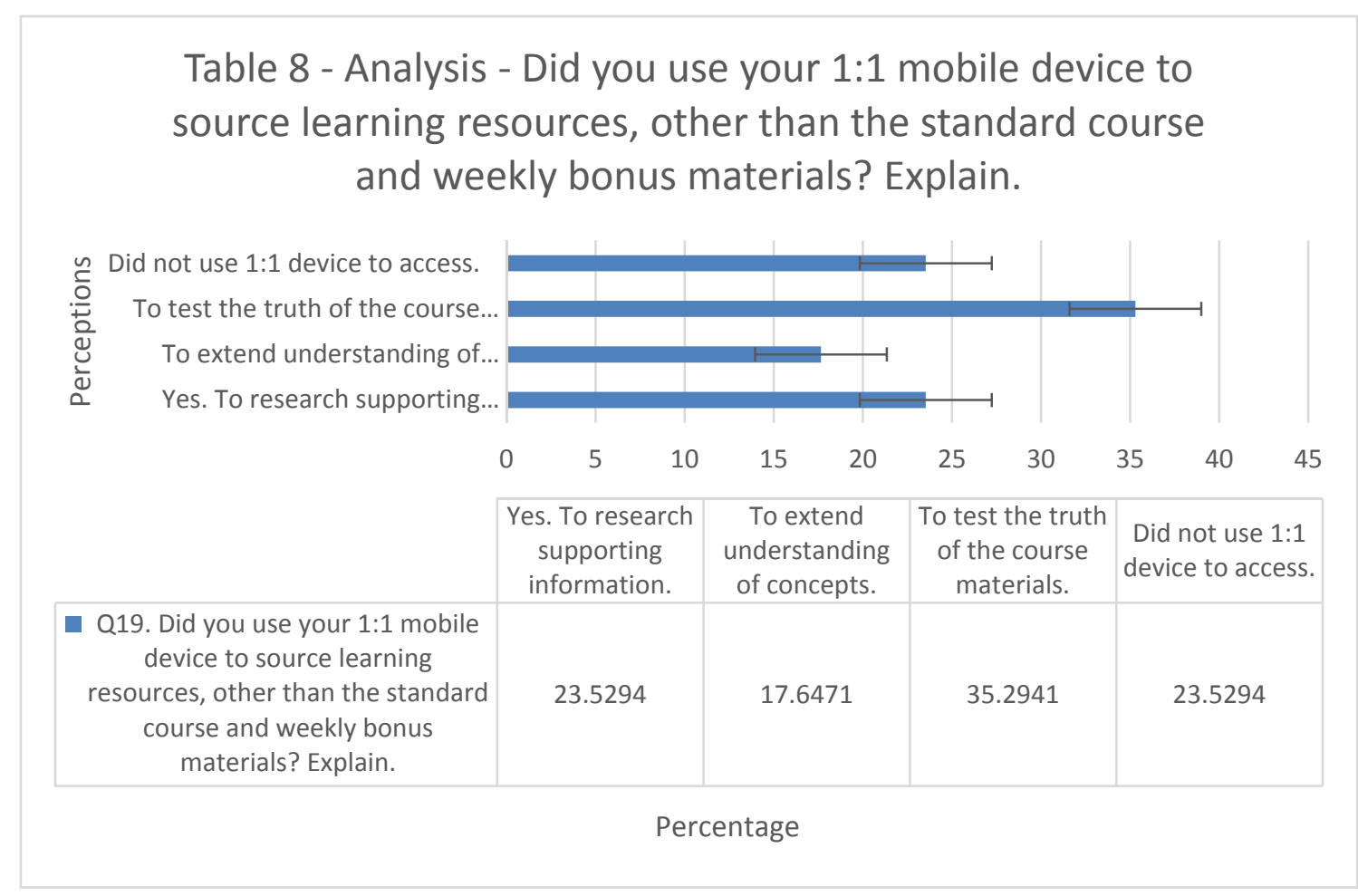

Table 8. Focus group responses: Did you use your 1:1 mobile device to source learning resources, other than the standard course and weekly bonus materials? Explain.

Yes. I used my 1:1 mobile device to research my electrical components.

Only to extend learning and research.

Yes. I used Google to search up extra information relevant to what I'm doing but not talked about in the lecture to us much detail, as I desired.

Yes. Resistor colour bands.

Yes, to source alternative learning material like 'Practical Electronics for Inventors' by Paul Scherz and Simon Monk.

Yes. Clarification on specific concepts and a wide variety of discussion forums are available through web searches.

Sometimes to fill in some gaps with the lectures on transistors.

Yes, extra follow on material from bonus material from same content creators.

Yes. I used YouTube to find other resources.

Yes, tutorials on YouTube and extra information on various websites to confirm content. 


\section{Discussion}

1:1 mobile technologies are evolving into a useful learning tool, and the supporting software applications are empowering learners to show evidence of their ability to think critically and express creativity. It is essential curriculum priorities aiming to leverage the benefits of 1:1 mobile devices, need to consider the link between learning motivations, critical thinking skills and creating a safe learning space for creativity to flourish. Researchers such as those mentioned in this research study, all agree on the importance of the role curriculum development has on equipping active learners to seamlessly integrate technology. Whilst there is a considerable disparity between institutions use of technology, the fundamental issue is ensuring digital literacy and the need to explicitly teach learners how to apply critical thinking skills as a priority to normalizing expressions of creativity. Implementing 1:1 mobile device into the curriculum as a tool to support learning must be carefully planned out, avoiding ad hoc fallacies that student outcomes will improve from its usage, and must be supported with understandings about how learners want to use the technology and supporting software APPS. Whilst there is no evidence in the literature to support the view that a students' ability to think critically and creatively is directly attributed to the use of 1:1 mobile devices; technology is becoming a persuasive tool that empowers learners to show evidence of their cognitive processes. Student perceptions play a greater role in their acceptance of 1:1 mobile devices, and curriculum developers have an opportunity to consider the motivational variables that create a positive (perceptions) environment to minimize learning anxiety, increase collaboration, promote sharing of resources and creation of digital artefacts, improve a shared digital vocabulary and importantly, the fostering of a culture of shared values and beliefs where creativity can be expressed without fallacy based criticism. Table 9 . Reasons to recommend use of 1:1 mobile devices for learning provides some suggested reasons based on learner perceptions as to their importance in the 'private' and 'public' learning space. Mobile devices are compatible with self-directed learning principles, helps learners with the creation and organization of digital artefacts, it supports different learning styles, it encourages independence to source additional educational sources, it complements traditional learning methods (Textbook learning), it facilitates student capacity to access knowledge, and importantly, improves access to different learning spaces at any time. Whilst educational research on the uses of 1:1 mobile technologies is primarily based on student perceptions, to improve student outcomes, they cannot be dismissed by curriculum developers.

Table 9. Reasons to recommend use of 1:1 mobile devices for learning and responses

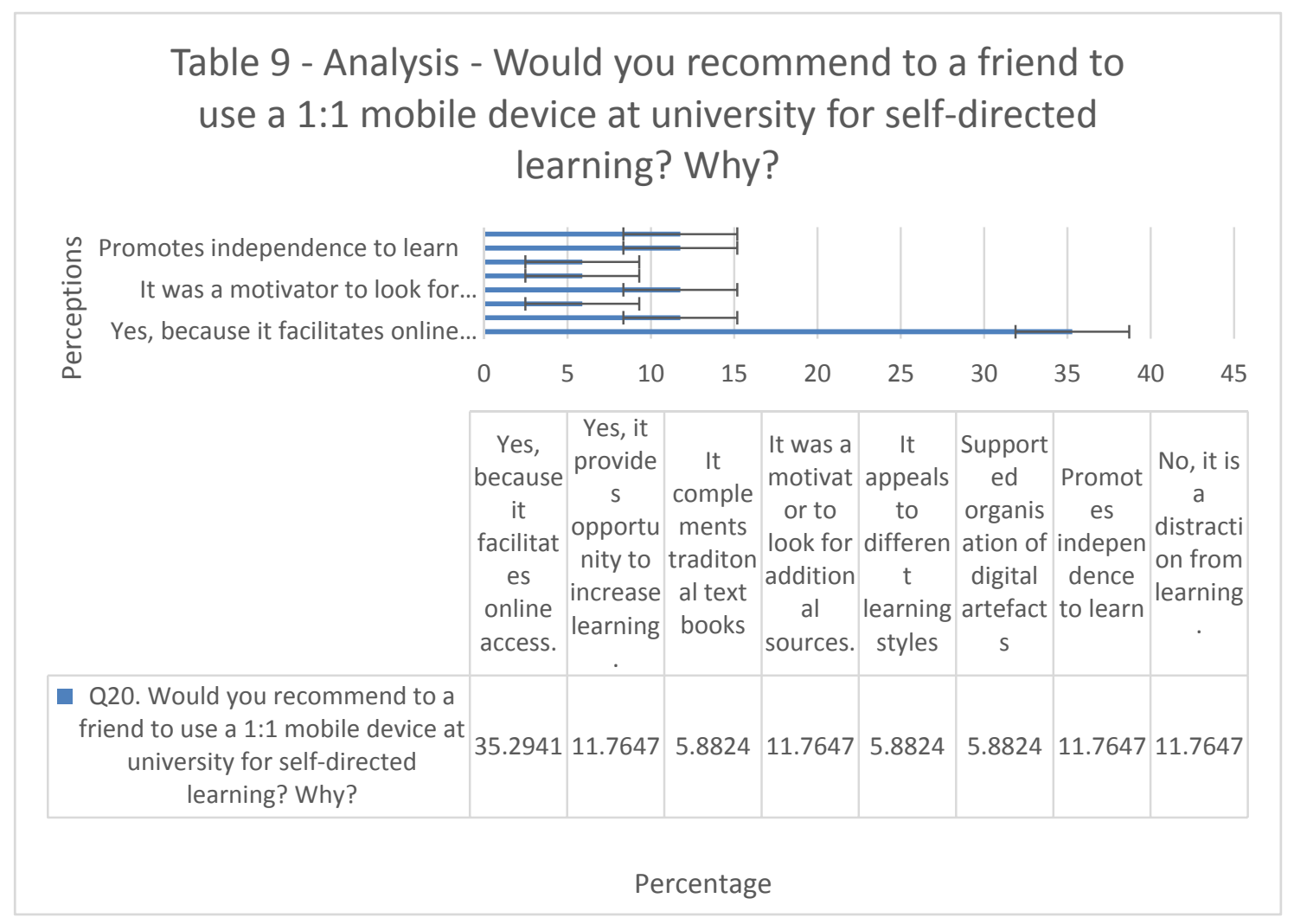


Table 9. Focus group responses: Would you recommend to a friend to use a 1:1 mobile device at university for self-directed learning? Why?

It gives you access to all your lecturer notes, and to the Internet which gives you a vast range of information.

Yes, due to access and convenience.

Yes, because it makes studying so much more efficient and it's easy to use as well as providing more opportunities to learn extra information.

No. To many distractions using a computer/laptop or library resource is more efficient.

Yes, as it compliments traditional resources (textbooks, etc.) and makes the information more accessible.

Yes, frequently. Any way to supplement learning should be encouraged.

Depends on what you are more comfortable using. If that is why they are use too, then Yes, I would recommend it. Though I didn't use a 1:1 device much; more a laptop for my studies and research.

It depends on the style of learning they wish to do.

Yes, that there are extra materials available.

Yes, because with my own experience it was really helpful.

Yes. It provides a secure and reliably way to manage your digital tools and works.

I would recommend a portable laptop (13 inch), over a phone or tablet.

Yes, because it helps with independence, and control over your own learning.

Yes. It allows us to take more control of our learning and allows us to always be able to access course information.

Yes. Ease of use. Practicality. Most courses now provide online content.

Yes, as it helped me.

Very modern way of working and easy.

Table 10. 1:1 mobile device learning integration summarizes the relationship between learning motivational variables and desired critical thinking skills:

Table 10. 1:1 mobile device learning integration

\begin{tabular}{ll}
\hline (Firipis) et. al. (2017) Motivational Variables & Marzano (1994) Critical Thinking Skills \\
Pre-conditioning to Learn & Metacognition-Knowledge \\
Extrinsic &
\end{tabular}

Extrinsic

Intrinsic

Recognition

Self-regulation and Active Learning

Feedback

Collaboration

Motivational Conflict

Setting Learning Goals

Learning Styles

Choice and Personal Interests

Environmental Factors

Social Orientation-Collaboration

Outcome Expectancy

Career Goals

Teacher Role Model

Structured v's Unstructured Learning Space

Cultural Values and Beliefs

Gender Identity

Reference: Firipis et. al. (2017)-Influence of Critical Thinking on Creativity when using 1:1 Mobile Devices for

Learning. Marzano, R. J. (1994). Using dimensions of learning to create performance tasks. Dimensions of

Learning [On-line]: http://kusd.kusd.edu/unique/dol/newsletter2.html 
Integrating the use of 1:1 mobile devices into the curriculum empowers learners to normalize familiar technology tools perceived as a value-add to their learning experience. It supports collaboration to engage in meaningful conversations to foster critical thinking. Further, 1:1 mobile device technology is compatible with self-directed learning principles.

\section{Conclusion}

Educators engaged in curriculum design will benefit from this research study to reconsider best practice teaching and learning strategies when considering the integration of 1:1 mobile device technology. The learning space in all its definitions (physical or virtual) is requiring greater attention in order to remain competitive with an international cross border research and education community. Technology integration relies on a commitment to on-going research and development of software and hardware platforms. The online delivery of educational resources and artefacts will continue to challenge our perceptions of the known learning space. Virtual learning spaces will become the future, and technology will evolve driven by market forces. This research study will assist further discussion about applying critical thinking skills when using mobile technology. It is exciting to reflect on the progress of education as a valuable commodity in an online global ecology.

\section{Disclosure Statement}

The authors of this research study acknowledge they have no financial interest or benefit arising from the direct application of this research.

\section{References}

Bloom, B.S. (1956). Taxonomy of educational objectives. Handbook I: Cognitive domain. New York: McKay.

Bourlard, H., Krishnamurthy, V., Sun, Y., Zhao, H.V., \& Liu, K.J.R. (2012). A technological revolution: social learning and networking. IEEE Signal Processing Magazine, 29(2), 20-21. https://doi.org/10.1109/MSP.2011.943584

Cain, J., \& Policastri, A. (2011). Using Facebook as an informal learning environment. American Journal of Pharmaceutical Education, 75(10), 207. https://doi.org/10.5688/ajpe7510207

Carrol, T.M. (1989). Critical thinking: Promoting it in the classroom. ERIC Digest. Retrieved from http://ericae2.educ.cua.edu/edo/ed306554.htm

Casey, G. (2012). Thinking Critically about Critical Thinking. In Shaughnessy, Michael (Ed.), Critical Thinking and Higher Order Thinking: A Current Perspective (pp. 23-39). Nova Science Publishers.

Chan, T.W., Roschelle, J., Hsi, S., Kinshuk, S.M., Brown, T., Patton, C., ... Hoppe, U. (2006). One-to-one technology enhanced learning: An Opportunity for global research collaboration. Research and Practice in Technology-Enhanced Learning, 1(1), 3-29. https://doi.org/10.1142/S1793206806000032

Clarke, J.H. (1990). Patterns of thinking: Integrating learning skills in content teaching. Boston: Allyn and Bacon.

Costa, A.L. (1990). Forward. In J. H. Clarke, (Ed.), Patterns of thinking: Integrating learning skills in content teaching (pp. xi-xiii). Boston: Allyn and Bacon.

Cotton, K. (1997). Teaching thinking skills. School Improvement Research Series. Retrieved from http://www.nwrel.org/scpd/sirs/6/cu11.html

Crowl, T.K., Kaminsky, S., \& Podell, D.M. (1997). Educational psychology: Windows on teaching. Madison, WI: Brown and Benchmark.

Dewey, J. (1933). How we think: A restatement of the relation of reflective thinking to the educative process. Boston: D.C. Heath and Company.

Elder, L. (2012). Critical Thinking: On the need for a minimalist, Comprehensive, Integrated Framework. In Shaughnessy, Michael (Ed.), Critical Thinking and Higher Order Thinking: A Current Perspective (pp. 1-23). Nova Science Publishers, Inc.

Elder, L., \& Paul, R. (2009). The thinker's guide to analytic thinking: how to take thinking apart and what to look for when you do. Dillon Beach: Foundation for Critical Thinking Press.

Ennis, R.H. (1996). Critical Thinking. Upper Saddle River, NJ: Prentice Hall. In Esterle \& Clurman (Eds.), Conversations with critical thinkers (pp.4-9). San Francisco, CA: The Whitman Institute. 
Firipis, A., Chandrasekaran, S., \& Joordens, M. (2017). 1:1 Mobile Device Learning Integration. Influence of Critical Thinking on Creativity and Its Application Using Learning Interventions to Influence Student's Perceptions Of Learning When Using 1:1 Mobile Devices, 13.

Fogarty, R., \& McTighe, J. (1993). Education teachers for higher order thinking: The three-story intellect. Theory into Practice, 32(3), 161-169. https://doi.org/10.1080/00405849309543592

Gagné, R.M., Briggs, L.J., \& Wager, W.W. (1988). Principles of instructional design. New York: Holt, Rinehart and Winston, Inc.

Gick, M.L., \& Lockhart, R.S. (1995). Cognitive and affective components of insight. In R.J. Sternberg \& J.E. Davidson (Eds.), The nature of insight (pp. 197-229). Cambridge, MA: The MIT Press.

Glaser, E. (1941). An experiment in the development of critical thinking. Columbia University: Bureau of Publications, Teacher's College.

Gruber, H.E. (1995). Insight and affect in the history of science. In R.J. Sternberg \& J.E. Davidson (Eds.), The nature of insight (pp. 396-433). Cambridge, MA: The MIT Press.

Haladyna, T.M. (1997). Writing test items to evaluate higher order thinking. Boston: Allyn and Bacon.

Jacobs, S.S. (1994). Technical characteristics and some correlates of the California critical thinking skills test, forms $a$ and $b$. (ERIC Document Reproduction Service No. ED 373 631).

Kahneman, D., Slovic, P., \& Tversky, A. (1982). Judgment under uncertainty: heuristics and biases. Cambridge: Cambridge University Press. https://doi.org/10.1017/CBO9780511809477

Kauchak, D.P., \& Eggen, P.D. (1998). Learning and teaching: Research-based methods (3rd ed.). Boston: Allyn and Bacon.

King, F.J., Rohani, F., \& Goodson, L. (1997). Statewide assessment of listening and verbal communication skills, information literacy skills, and problem-solving skills. Tallahassee: Florida State University.

Koh, E., Loh, J., \& Hong, H. (2013). A Snapshot approach of a smartphone-enabled implementation. Research and Practice in Technology Enhanced Learning, 8(1), 91-115.

Kukulska-Hulme, A., \& Traxler, J. (2013). Design principles for mobile learning. In H. Beetham \& R. Sharpe (Eds.), Rethinking Pedagogy for a Digital Age: Designing for 21st Century Learning (2nd ed., pp. 244-257). New York, NY: Routledge.

Lea, M.R., \& Jones, S. (2011). Digital literacies in higher education: exploring textual and technological practice. Studies in Higher Education, 36(4), 377-393. https://doi.org/10.1080/03075071003664021

Legg, S.M. (1990). Issues in critical thinking. Paper prepared for the College of Pharmacy at the University of Florida, Gainesville, FL.

Lewis, A., \& Smith, D. (1993). Defining higher order thinking. Theory Into Practice, 32(3), 131-137. https://doi.org/10.1080/00405849309543588

Marzano, R.J. (1994). Using dimensions of learning to create performance tasks. Dimensions of Learning. Retrieved from http://kusd.kusd.edu/unique/dol/newsletter2.html

McPeck, J. (1990). Critical thinking and subject specificity: A reply to Ennis. Educational Researcher, 19(4), 10-12. https://doi.org/10.3102/0013189X019004010

Ng, W. (2013). Conceptualizing mLearning Literacy. International Journal of Mobile and Blended Learning, 5(1), 1-20. https://doi.org/10.4018/jmbl.2013010101

Ogata, H., Li, M., Hou, B., Uosaki, N., El-Bishouty, M., \& Yano, Y. (2011). SCROLL: Supporting to share and reuse ubiquitous learning log in the context of language learning. Research and Practice in Technology Enhanced Learning, 6(2), 69-82.

Pachler, N. (2010). The Socio-cultural ecological approach to mobile learning: An Overview. In B. Bachmair (Ed.), Medienbildung in neuen Kulturräumen (pp. 153-167). Berlin, Germany: Springer-Verlag. https://doi.org/10.1007/978-3-531-92133-4_11

Patrick, J.H. (1986). Critical thinking in the social studies. ERIC Digest No. 30. Retrieved from http://ericae.net/db/digs/ed272432.htm

Paul, R. \& Elder, L. (2007). Critical thinking: tools for taking charge of your learning and your life (2nd ed.). Upper Saddle River, NJ: Pearson Prentice Hall. 
Paul, R., \& Elder, L. (2008). The Thinkers' Guide to Critical and Creative Thought. Dillon Beach, CA: Foundation for Critical Thinking Press.

Paul, R.W., \& Elder, L. (2009). The miniature guide to critical thinking concepts \& tools (6th ed.). Dillon Beach, CA: The Foundation for Critical Thinking.

Pavlenko, A. (2009). Conceptual representation in the bilingual lexicon and second language vocabulary learning. In A. Pavlenko (Ed.), The bilingual mental lexicon: Interdisciplinary approaches (pp. 125-160). Bristol, UK: Multilingual Matters.

Pogrow, S. (1990). Challenging at-risk students: Findings from the HOTS program. Phi Delta Kappan, 71(5), 389-397.

Pogrow, S., \& Buchanan, B. (1985). Higher-order thinking for compensatory students. Educational Leadership, 43(1), 40-43.

Siegel, H. (1988). Educating reason: rationality, critical thinking and education (pp. 32-39). New York: Routledge, Chapman and Hall, Inc.

Topping, K. (2005). Trends in Peer Learning. Educational Psychology, 25(6), 631-645. https://doi.org/10.1080/01443410500345172

Wang, C., \& Chen, C., (2013). Effects of Facebook tutoring on learning English as a second language. IADIS International Conference e-Learning.

Wodzicki, K., Schwammlein, E., \& Moskaliuk, J. (2012). “Actually, I wanted to learn”: study-related knowledge exchange on social networking sites. Internet and Higher Education, 15(1), 9-14. https://doi.org/10.1016/j.iheduc.2011.05.008

Wong, L.H. (2013). Analysis of students' after-school mobile-assisted artefact creation processes in a seamless language learning environment. Educational Technology \& Society, 16(2), 198-211.

Wong, L.H., \& Looi, C.K. (2011). What seams do we remove in mobile assisted seamless learning? A Critical review of the literature. Computers \& Education, 57(4), 2364-2381. https://doi.org/10.1016/j.compedu.2011.06.007

Wong, L.H., Milrad, M., \& Specht, M. (2015). Seamless learning in the age of mobile connectivity. Singapore: Springer. https://doi.org/10.1007/978-981-287-113-8

Wozniak, S. (2014). How Steve Wozniak wrote BASIC for the original Apple from scratch. Retrieved December 12, 2017, from https://www.gizmodo.com.au/2014/05/how-steve-wozniak-wrote-basic-for-the-original-apple-from-scratch/

\section{Copyrights}

Copyright for this article is retained by the author(s), with first publication rights granted to the journal.

This is an open-access article distributed under the terms and conditions of the Creative Commons Attribution license (http://creativecommons.org/licenses/by/4.0/). 